\title{
Taming the Monster: Need for Africa-initiated, Africa-led HIV Vaccine Research and Development Advocacy in Africa
}

Chidi Victor Nweneka*

National Agency for the Control of AIDS, Abuja, Nigeria

${ }^{*}$ Corresponding author: Chidi Victor Nweneka, Deputy Director (Policy \& Strategy), National Agency for Control of AIDS, Plot 823, Ralph Shodeinde Street, Central Business District, Abuja, Nigeria, Tel: 23494613703; E-mail: chidele@hotmail.com

Received date: 26 May 2014; Accepted date: 30 June 2014; Published date: 04 July 2014

Copyright: ( 2014 Nweneka CV. This is an open-access article distributed under the terms of the Creative Commons Attribution License, which permits unrestricted use, distribution, and reproduction in any medium, provided the original author and source are credited.

\begin{abstract}
Scientific advancement has led to tremendous improvements in the life expectancy of people living with HIV. In addition, there is renewed hope that with combination prevention which includes early initiation of ART and ARVbased PrEP, we may have begun to see the end of the deadly epidemic. However, it is also widely acknowledged that we cannot end AIDS without an effective vaccine. While strenuous efforts are being made in different parts of the world to advance the HIV vaccine R\&D agenda, Africa has been largely playing a spectator role. Considering that Africa with less than $20 \%$ of the global population hosts approximately $70 \%$ of people living with HIV, one would expect Africa to be in the fore-front for the search of an HIV vaccine. Getting African governments to key into the HIV vaccine research and development agenda will require strong advocacy. This paper reviews the status of HIV epidemic with particular reference to Africa, highlights the continued need for an effective HIV vaccine and advocates for the development of a focused Africa-initiated, Africa-driven HIV vaccine advocacy strategy for Africa.
\end{abstract}

Keywords: HIV vaccine; HIV vaccine research; AIDS

\section{Introduction}

The Human Immunodeficiency Virus (HIV), perhaps the most important modern day plague has been with us for over 30 years. During this period, it has claimed over 36 million lives, orphaned many more, and crippled the economies of many of the most affected countries. As at the end of 2012, 35.3 million [32.2-38.8 million] people were living with HIV globally (WHO. http:// www.who.int/gho/hiv/epidemic_status/cases_all/en/, Accessed $06 / 05 / 2014)$. From what was initially a 'gay-men's disease' [1,2], HIV has become a primarily Africa problem with nearly $70 \%$ of the people living with HIV residing in Africa. (http://www.unaids.org/en/media/ unaids/contentassets/documents/epidemiology/2013/gr2013/

UNAIDS_Global_Report_2013_en.pdf, Accessed 06/05/2014). Figure 1 compares the trend of HIV prevalence rates in sub-Saharan Africa (SSA) to the Global trend. Several scientific breakthroughs, including antiretroviral treatment (ART) and several prevention modalities have improved the outlook for people living with HIV. In recent years, there have been further exciting developments in the field of HIV and Acquired Immunodeficiency Syndrome (AIDS) prevention and treatment that the discourse has now moved to the possibility of ending AIDS [3-5]. Some of these new discoveries include the finding that early initiation of anti-retroviral therapy in the infected partner of HIV sero-discordant couples could reduce the risk of acquiring HIV by the uninfected partner by $96 \%$ [6]. The Partners PrEP Study also reported that the use of oral tenofovir as a prophylaxis in HIV-1 serodiscordant couples provided $67 \%$ protection from HIV acquisition for participants while those given a combination of tenofovir and emtricitabine had $75 \%$ protection [7]. The results of these and similar studies examining the protective effects of pre-exposure prophylaxis were recently confirmed in a meta-analysis [8]. A study on the potential use of $1 \%$ tenofovir gel as a vaginal microbicide reported $39 \%$ protection from HIV among women [9]. Medical male circumcision has also been shown to significantly reduce the risk of acquisition of HIV in men [10-13]. However, as was recently emphasised [4], an effective HIV vaccine still remains key in ending AIDS. Considering that Africa, with less than $20 \%$ of the global population accounts for more than two-thirds of the global burden of HIV, Africa's contribution to the global fight to end AIDS, and especially in the search for an effective HIV vaccine is very critical. While there has been remarkable improvement in many African governments' contribution to the HIV and AIDS response, the response to the search for an effective HIV vaccine is still at best rudimentary, with the exception of South Africa.

Advocacy has always played a crucial role in defining and driving the HIV/AIDS response from the time of the discovery of AIDS to date. Getting African governments to key into the HIV vaccine research and development agenda will require strong advocacy. This paper reviews the status of HIV epidemic with particular reference to Africa, highlights the continued need for an effective HIV vaccine and advocates for the development of a focused Africa-initiated, Africadriven HIV vaccine advocacy strategy for Africa.

\section{The HIV Epidemic - From 1981 to Date}

AIDS was first reported in 1981 in the United States of America among a group of young men who have sex with men [14,15]. In 1983, the virus that causes AIDS was isolated [16,17]; this was quickly followed by the development of assays for detecting the HIV virus. Within a few years of the first reports of AIDS, HIV infection was reported in other populations and countries; and by the end of 2009, HIV has spread to nearly all countries of the world (UNAIDS Report on the Global AIDS Epidemic, 2010. http://www.unaids.org/ documents/20101123_GlobalReport_em.pdf, Accessed 06/05/2014). The worst impact of HIV was felt in Africa where AIDS-related illness was responsible for the deaths of millions especially within the 
productive age groups, with devastating consequences on the socioeconomic conditions of the worst affected countries.

In 2012, About 2.3 million people became infected with HIV globally, out of which 1.6 million were in SSA. The progression of the epidemic has not been uniform across SSA. In some countries in SSA, the prevalence rates have stabilized; in others it has decreased; and in a third category of countries, the prevalence rates are increasing (Figure 2). Sadly, SSA, with only about $12 \%$ of the global population, still accounts for $68 \%$ of the global burden of HIV; $70 \%$ (1.9 million) of all new HIV infections in 2010 were in SSA; SSA women still bear the brunt of HIV, constituting 59\% of all adults living with HIV in 2010; more than one million people still die from AIDS-related causes in SSA; heterosexual transmission remains the predominant mode of HIV infection in SSA; and injecting drug use is becoming an important factor in HIV transmission in Africa.

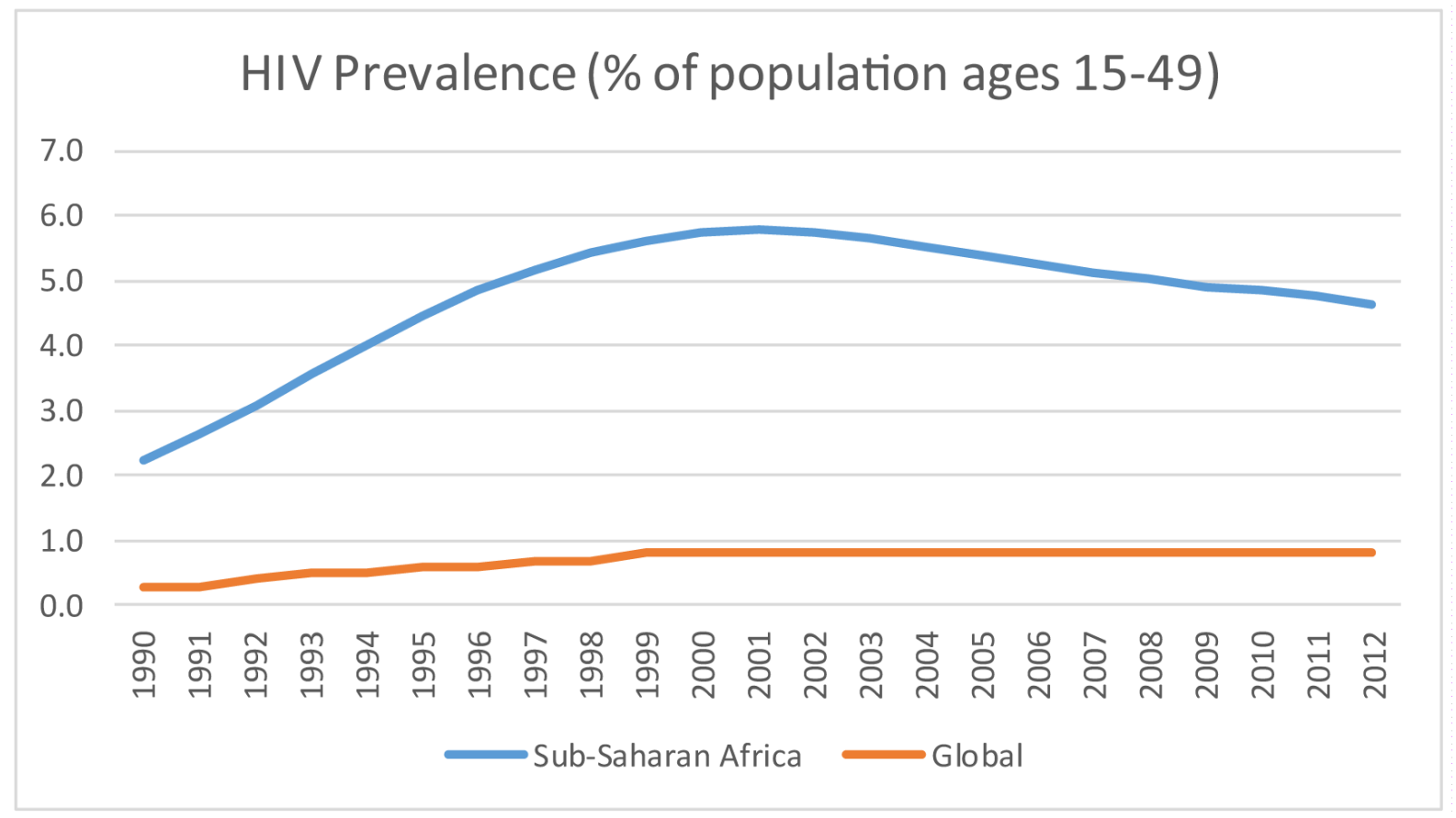

Figure 1: Prevalence of HIV 1990 - 2012 in Sub-Saharan African Countries (Data Source: World Bank (http://data.worldbank.org/indicator/ SH.DYN.AIDS.ZS, accessed 24 April, 2014).

\section{Controlling the epidemic in Africa - an effective HIV vaccine is still needed}

Traditionally, HIV control measures have included abstinence from sexual intercourse, mutual faithfulness, avoidance of multiple concurrent partners, use of barrier methods (male and female condoms), Voluntary Counselling and Testing, prevention of mother to child transmission of HIV, proper handling and disposal of sharps, and screening and treatment for sexually transmitted infections (STIs). One common determinant of the success of these traditional HIV prevention methods is behaviour. Unfortunately, behaviour change is difficult; hence the continued persistence of HIV infection even when condom has been shown to confer up to $95 \%$ protection when used consistently [18-21]. Recently, newer methods of HIV prevention have been introduced, including early initiation of highly active antiretroviral therapy (HAART), voluntary medical male circumcision and anti-retroviral drugs (ARV)-based pre-exposure prophylaxis (PrEP).

While these new prevention methods have great potentials, alone and in combination, to reduce the number of new infections, and contribute towards achieving zero HIV infection, several factors could affect their efficacy. For example, in settings where male circumcision is a cultural norm, male circumcision as an HIV intervention method will contribute little to the control of the epidemic. In addition, male circumcision benefits only males: females are not protected [22,23]. Reports indicate that the number of new HIV infections is still higher than the number of new individuals being placed on ART, further increasing the number of people that will eventually require ARVs (UNAIDS report on the global AIDS epidemic 2013.

http://www.unaids.org/en/media/unaids/contentassets/documents/ epidemiology/2013/gr2013/UNAIDS_Global_Report_2013_en.pdf, Accessed 06/05/2014). More than half of the people requiring ARVs in SSA cannot get them because of financial reasons; reducing the likelihood of various African governments' being able to fund PrEP for all the populations at risk. For example, in an African country with a population in excess of 30 million, if we assume that 5 million people are at risk of HIV, and that the cost of Truvada has been very heavily subsidized such that it costs only $\$ 100$ per annum per person. This will translate to $\$ 500$ million per annum on PrEP alone! Clearly, cost will be a major factor in the roll out of PrEP in many SSA countries. Primary ARV resistance is another problem to consider while rolling out PrEP and other ARV-related interventions. Harmers et al. [24,25] have determined that in many SSA countries, there is a high prevalence of primary resistance to existing ARVs. Logistics 
Page 3 of 6

considerations are also potential limiting factors for the success of current and proposed control measures. In much of SSA, the health systems are inefficient and poorly funded, monitoring of performance is poor and the sustenance of such services is still heavily donor dependent. Above all, these methods also require a strong behavioral component.

Future prevention options being considered include vaginal and rectal microbicides, and preventive/therapeutic HIV vaccines. An effective microbicide will be an important addition to the HIV prevention armamentarium. However, issues to contend with will include the strong behaviour component similar to the male and female condom, the high prevalence of gender-based violence in SSA, and cultural issues. Although it is difficult to permute how much a microbicide would cost at present, cost and acceptability are other issues that could be important in their effectiveness.

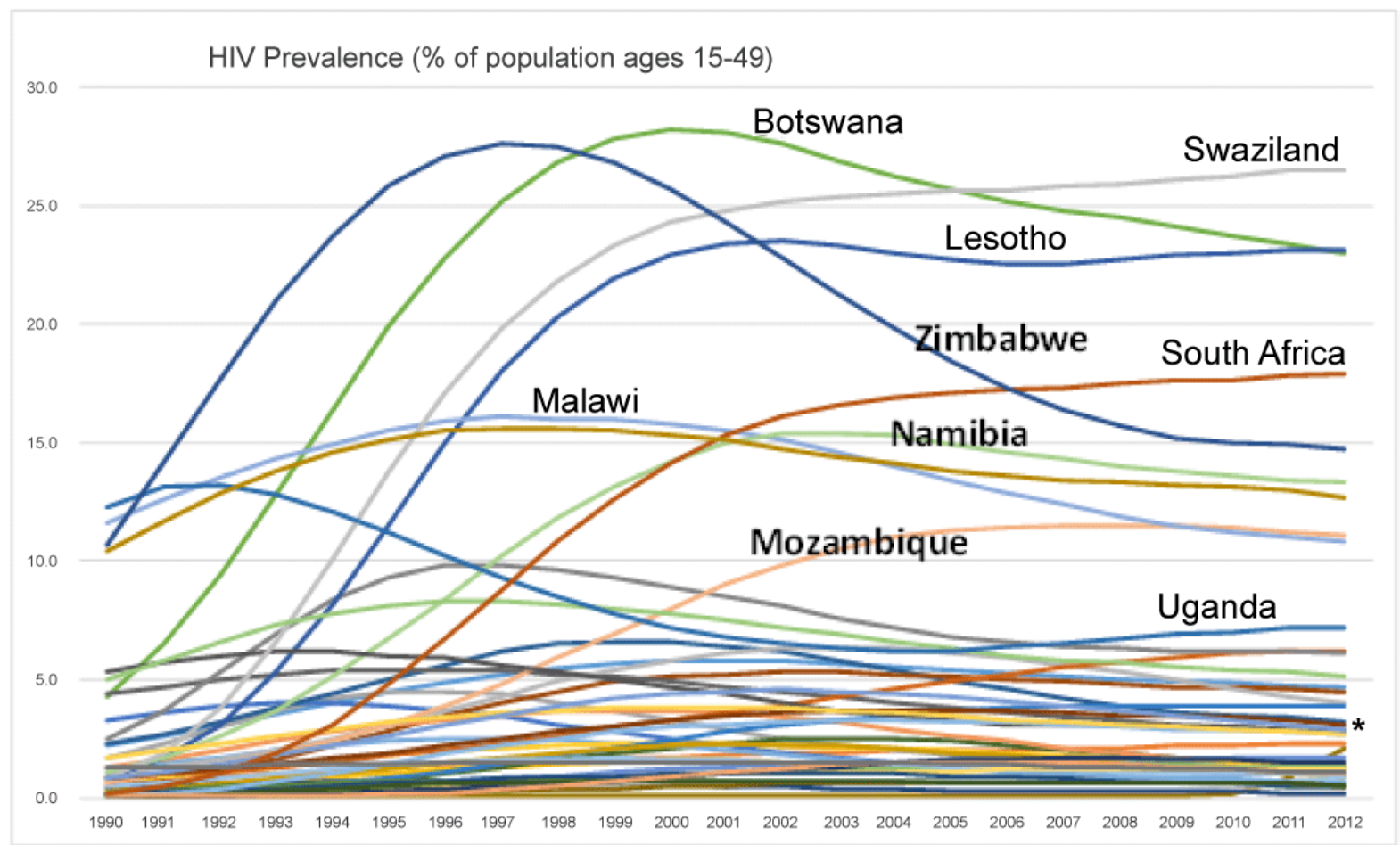

Prevalence of HIV 1990 - 2012 in Sub-Saharan African Countries (Data Sources: World Bank (http://data.worldbank.org/indicator/SH.DYN.AIDS.ZS, accessed 24 April, 2014)

\section{* = Nigeria}

Figure 2: Prevalence of HIV 1990 - 2012 in Sub-Saharan African Countries

\section{Why an effective HIV vaccine is the most preferred for Africa}

Vaccines have generally been shown to be the most cost-effective public health tools $[26,27]$. Several studies have shown that in low and middle income countries, vaccinations confer immense economic benefits and are generally cost effective [28,29]. Stack et al. [30] have estimated that during the decade of vaccines, vaccination of children against the commonest infectious diseases in developing countries could avert as many as 426 million cases of illness, save 6.4 million lives valued at $\$ 231$ billion (range: $\$ 116-\$ 614$ billion), with cost savings of $\$ 6.2$ billion for treatment, and $\$ 145$ billion for loss in productivity [26]. Considering the number of people at risk of HIV infection in SSA, the economic benefit of an effective HIV vaccine could potentially dwarf the current estimates. Indeed, several modelling studies have shown that even a moderately efficacious HIV vaccine given to a limited number of people could still avert millions of new infections https://www.iavi.org/InformationCenter/ Publications/Documents/Global\%20Impact\%20Brief.pdf) [31].
The expanded program on immunisation has developed a very effective network for delivering vaccines even to the remotest parts of Africa. This network can be effectively utilized to deliver HIV vaccine to a large number of people within a short time, making it unnecessary for the development of new structures for rolling out an HIV vaccine once one has been licensed. The behavioral component associated with delivering HIV vaccine to those who need it is very minimal compared to the other prevention methods. An effective HIV vaccine will immediately address the difficulties associated with stigma and discrimination as it will be given to everybody regardless of the individual's sero-status. In other words, people will likely see it as part of the routine immunization program than a program for some special people.

\section{Challenges with HIV vaccine advocacy in Africa}

- The scientific challenges facing HIV vaccine research have been well reviewed by several authors [32-34]. These include the 
absence of an ideal animal model, poor understanding of the correlates of protective immunity, the intense variability of the HIV organism, the virus' ability to integrate into the host genome, viral efficiency to quickly overwhelm the host's immune system and establish reservoirs of infection, and the concealment of the conserved antibody targets on the outer envelope. The magnitude of these scientific challenges and the resultant disappointing results from all the HIV vaccine clinical trials except the RV144 Thai trial has understandably generated a lot of scepticism on the feasibility of an effective HIV vaccine [35]. Such scepticism makes it difficult to effectively advocate for the continuation of HIV vaccine research especially in resource poor countries of SSA Nonscientific challenges which have hindered effective HIV vaccine advocacy in Africa include:

- Continued negative results from HIV vaccine research studies. In more than two decades of HIV vaccine research, there have been very few exciting moments. One particularly bright moment in the HIV vaccine R\&D enterprise was the announcement in 2009 of the results of the RV144 Thai trial [36], which showed for the first time that an effective HIV vaccine is feasible. Prior to this time, it had been a series of discouraging news with each succeeding trial showing either a null or a negative effect of the agents tested. The recent discontinuation of HVTN 505 [37] was another sore moment in HIV vaccine research advocacy. Such failures have led to discouragement and skepticism among HIV vaccine R\&D advocates.

- Cost of doing HIV vaccine research: HIV vaccine research is a very expensive venture. From 2005 to 2012, the total funding for HIV preventive research was $\$ 7$ billion compared to 2.4 billion for research into microbicides, pre-exposure prophylaxis, adult male circumcision and treatment as prevention combined.Cost considerations could discourage many interested scientists and most of the affected countries to venture into HIV vaccine research, considering that many of these countries have been unable to fund their national HIV response plans..

- Competing interests: With limited resources and several public health programs such as the millennium development goals (MDG) and other health issues to address, coupled with the surge of excitements from results of PrEP and other HIV prevention research, there is a strong push to stop 'wasting' money on HIV vaccine research but rather invest such funds on proven HIV prevention methods. However, several studies have shown that the cost savings from an effective HIV vaccine will ultimately outweigh the cost of developing the vaccine. [38] (Jennie Aylward, IAVI Policy Briefs, http://pdpaccess.org/wp-content/uploads/ 2012/11/Aylward_AIDS-Vaccines-Exploring-the-Potential-CostBenefit.pdf, Accessed 04/05/14).

- Lack of strong Leadership in the HIV vaccine research and development (R\&D) advocacy efforts in Africa: Anecdotal evidence suggests that there is limited knowledge of the concept of HIV vaccines among key African stakeholders, including policy makers and HIV advocates. Unfortunately, the mechanism to help them understand, and therefore support the HIV vaccine R\&D agenda is largely lacking. Previous efforts to bridge this gap has been hampered by vested interests and political subterfuge. This has resulted in the failure to develop an adequate coordinating mechanism for HIV vaccine R\&D advocacy in Africa. In North America and Europe, on the one hand, there is a well-organized HIV vaccine advocacy community that is able to effectively articulate the case for continued support for HIV vaccines. Africa, on the other hand, lacks such a well-organized well-coordinated mechanism. What presently exist are pockets of advocacy activities with very little synergy. Previous international efforts to put such coordinating mechanism in place collapsed for reasons beyond the remits of this brief paper. One of the consequences of the weak leadership in HIV vaccine advocacy efforts in Africa is lack of country ownership and accountability by African governments. Since the advent of the HIV/AIDS pandemic, superior argument by advocates have always driven the response by governments and philanthropists. This is true for access to anti-retroviral treatment [39], condoms etc. This is also true for microbicide research [40]. The situation cannot be different for vaccine research. One way to counter the perceived lack of interest by African governments to fund HIV vaccine R\&D is to develop a consistent, focused, longterm Africa-led HIV vaccine R\&D advocacy. Unfortunately, this level of advocacy has not been allowed to thrive in Africa. There appears to be a lot of ambiguity and prevarication in the support for Africa-led efforts in addressing these issues especially in the area of advocacy. Such scenario can only breed mistrust which is counter-productive.

- Capacity gaps: There are several capacity gaps in Africa, including appropriate legal and regulatory frameworks for the conduct of HIV vaccine research. Although many African countries have developed National HIV Vaccine Plans, only few of these plans have been ever implemented. In addition, there is limited human capacity to support the conduct of more upstream research in Africa. While there have been efforts to build the research capacity of Africa, anecdotal evidence suggests that there is still limited involvement of African research community in HIV vaccine R\&D and poor recognition of the efforts of those engaged in one form or another with these efforts.

\section{Moving the HIV vaccine R\&D agenda forward: A three point agenda}

Agenda 1: Development of a long-term, focused, well-coordinated, Africa-initiated, Africa-led HIV vaccine R\&D advocacy. Such advocacy will target the highest ministerial level in Africa, corporate bodies, African philanthropists, and all the major stakeholders. The goals of the advocacy will be to

- To galvanize high level political support for HIV vaccine R\&D

- To educate policy makers on the process and challenges of HIV vaccine research

- To campaign, lobby and induce relevant stakeholders to address the various capacity gaps hampering HIV vaccine R\&D in Africa

- To facilitate the development and strengthening of effective partnership between Southern scientists and their counterparts in the South and in the North

In addition, the advocacy will seek to highlight the added value of HIV vaccine research to public health. For example, it could be argued that supporting HIV vaccine research and development could strengthen public health system, help to strengthen in-country capacity for research, improve provision of health care during trials and boost the economy of host countries in the form of job creation and improved revenues.

Agenda 2: Institute deliberate strategies to address the limited HIV vaccine pipeline, which has been shown to be one of the challenges hampering the discovery of an effective HIV vaccine. One of such strategies would be to diversify the players on the field. Rather than 
lumping all available funds into one single research project, research funders could consider several HIV vaccine related freedom to discover grants with very transparent and liberal eligibility criteria, possibly involving mentorship. Regional biotechnology incubation centers could be set up in Africa to encourage small groups of scientists to develop their potentials. Such small groups could make a huge difference if properly facilitated and integrated into the product discovery process.

Agenda 3: Build genuine country ownership of HIV vaccine research projects through effective partnerships, effective communication and enactment of policies to compel externally funded research projects to demonstrate adequate local involvement at all stages of the project before granting final approval to conduct the research.

\section{References}

1. Centers for Disease Control and Prevention (CDC) (2001) HIV and AIDS--United States, 1981-2000. MMWR Morb Mortal Wkly Rep 50: 430-434.

2. (2001) From the Centers for Disease Control and Prevention. HIV and AIDS--United States, 1981-2000. JAMA 285: 3083-3084.

3. Buse K, Blackshaw R, Kakkattil P (2013) World AIDS day 2013: "Getting to zero: ending AIDS". Indian J Med Res 138: 817-819.

4. Fauci AS, Marston HD (2014) Ending AIDS--is an HIV vaccine necessary? N Engl J Med 370: 495-498.

5. Cohen J (2013) Infectious diseases. Goal of ending AIDS gains traction. Science 342: 786-787.

6. Cohen MS, Chen YQ, McCauley M, Gamble T, Hosseinipour MC, et al. (2011) Prevention of HIV-1 infection with early antiretroviral therapy. N Engl J Med 365: 493-505.

7. Baeten JM, Donnell D, Ndase P, Mugo NR, Campbell JD, et al. (2012) Antiretroviral prophylaxis for HIV prevention in heterosexual men and women. N Engl J Med 367: 399-410.

8. Jiang J, Yang X, Ye L, Zhou B, Ning C, et al. (2014) Pre-exposure prophylaxis for the prevention of HIV infection in high risk populations: a meta-analysis of randomized controlled trials. PLoS One 9: e87674.

9. Abdool Karim Q, Abdool Karim SS, Frohlich JA, Grobler AC, Baxter C et al. (2010) Effectiveness and safety of tenofovir gel, an antiretroviral microbicide, for the prevention of HIV infection in women. Science 329: 1168-1174.

10. Bailey RC, Moses S, Parker CB, Agot K, Maclean I, et al. (2007) Male circumcision for HIV prevention in young men in Kisumu, Kenya: a randomised controlled trial. Lancet 369: 643-656.

11. Auvert B, Taljaard D, Lagarde E, Sobngwi-Tambekou J, Sitta R, et al. (2005) Randomized, controlled intervention trial of male circumcision for reduction of HIV infection risk: the ANRS 1265 Trial. PLoS Med 2: e298.

12. Gray RH, Kigozi G, Serwadda D, Makumbi F, Watya S, et al. (2007) Male circumcision for HIV prevention in men in Rakai, Uganda: a randomised trial. Lancet 369: 657-666.

13. Weiss HA, Quigley MA, Hayes RJ (2000) Male circumcision and risk of HIV infection in sub-Saharan Africa: a systematic review and metaanalysis. AIDS 14: 2361-2370.

14. Centers for Disease Control (CDC) (1982) A cluster of Kaposi's sarcoma and Pneumocystis carinii pneumonia among homosexual male residents of Los Angeles and Orange Counties, California. MMWR Morb Mortal Wkly Rep 31: 305-307.

15. Centers for Disease Control (CDC) (1981) Pneumocystis pneumoniaLos Angeles. MMWR Morb Mortal Wkly Rep 30: 250-252.

16. Barre-Sinoussi F, Chermann JC, Rey F, Nugeyre MT, Chamaret S, et al. (1983) Isolation of a T-lymphotropic retrovirus from a patient at risk for acquired immune deficiency syndrome (AIDS). Science. 220: 868-871.
17. Popovic M, Sarngadharan MG, Read E, Gallo RC (1984) Detection, isolation, and continuous production of cytopathic retroviruses (HTLVIII) from patients with AIDS and pre-AIDS. Science 224: 497-500.

18. Weller S, Davis K (2002) Condom effectiveness in reducing heterosexual HIV transmission. Cochrane database syst rev 1: CD003255.

19. Hearst N, Chen S (2004) Condom promotion for AIDS prevention in the developing world: is it working? Stud Fam Plann 35: 39-47.

20. Pinkerton SD, Abramson PR, Turk ME (1998) Updated estimates of condom effectiveness. J Assoc Nurses AIDS Care 9: 88-89.

21. Holmes KK, Levine R, Weaver M (2004) Effectiveness of condoms in preventing sexually transmitted infections. Bull World Health Organ 82: 454-461.

22. Wawer MJ, Makumbi F, Kigozi G, Serwadda D, Watya S, et al. (2009) Circumcision in HIV-infected men and its effect on HIV transmission to female partners in Rakai, Uganda: a randomised controlled trial. Lancet 374: 229-237.

23. Weiss HA, Hankins CA, Dickson K (2009) Male circumcision and risk of HIV infection in women: a systematic review and meta-analysis. Lancet Infect Dis 9: 669-677.

24. Hamers RL, Schuurman R, Sigaloff KC, Wallis CL, Kityo C, et al. (2012) Effect of pretreatment HIV-1 drug resistance on immunological, virological, and drug-resistance outcomes of first-line antiretroviral treatment in sub-Saharan Africa: a multicentre cohort study. Lancet infect dis12: 307-317.

25. Hamers RL, Sigaloff KC, Kityo C, Mugyenyi P, de Wit TF (2013) Emerging HIV-1 drug resistance after roll-out of antiretroviral therapy in sub-Saharan Africa. Curr Opin HIV AIDS 8: 19-26.

26. Ozawa S, Stack ML, Bishai DM, Mirelman A, Friberg IK, et al. (2011) During the 'decade of vaccines,' the lives of 6.4 million children valued at \$231 billion could be saved. Health Aff (Millwood) 30: 1010-1020.

27. Centers for Disease Control and Prevention (CDC) (1999) Ten great public health achievements--United States, 1900-1999. MMWR Morb Mortal Wkly Rep 48: 241-243.

28. Ozawa S, Mirelman A, Stack ML, Walker DG, Levine OS (2012) Costeffectiveness and economic benefits of vaccines in low- and middleincome countries: a systematic review. Vaccine 31: 96-108.

29. Deogaonkar R, Hutubessy R, van der Putten I, Evers S, Jit M (2012) Systematic review of studies evaluating the broader economic impact of vaccination in low and middle income countries. BMC Public Health 12: 878.

30. Stack ML, Ozawa S, Bishai DM, Mirelman A, Tam Y, et al. (2011) Estimated economic benefits during the 'decade of vaccines' include treatment savings, gains in labor productivity. Health affairs 30: 1021-1028.

31. Fonseca MG, Forsythe S, Menezes A, Vuthoori S, Possas C, et al. (2010) Modeling HIV vaccines in Brazil: assessing the impact of a future HIV vaccine on reducing new infections, mortality and number of people receiving ARV. PLoS One 5: e11736.

32. Koff WC (2012) HIV vaccine development: challenges and opportunities towards solving the HIV vaccine-neutralizing antibody problem. Vaccine 30: 4310-4315.

33. Munier CM, Andersen CR, Kelleher AD (2011) HIV vaccines: progress to date. Drugs 71: 387-414.

34. Kim JH, Rerks-Ngarm S, Excler JL, Michael NL (2010) HIV vaccines: lessons learned and the way forward. Curr Opin HIV AIDS 5: 428-434.

35. Burton DR, Desrosiers RC, Doms RW, Feinberg MB, Gallo RC, et al. (2004) Public health. A sound rationale needed for phase III HIV-1 vaccine trials. Science 303: 316 .

36. Rerks-Ngarm S, Pitisuttithum P, Nitayaphan S, Kaewkungwal J, Chiu J, et al. (2009) Vaccination with ALVAC and AIDSVAX to prevent HIV-1 infection in Thailand. N Engl J Med 361: 2209-2220.

37. Hammer SM, Sobieszczyk ME, Janes H, Karuna ST, Mulligan MJ, et al. (2013) Efficacy trial of a DNA/rAd5 HIV-1 preventive vaccine. N Engl J Med 369: 2083-2092. 
Citation: Nweneka CV (2014) Taming the Monster: Need for Africa-initiated, Africa-led HIV Vaccine Research and Development Advocacy in Africa. J Vaccines Vaccin 5: 243. doi:10.4172/2157-7560.1000243

Page 6 of 6

38. Long EF, Owens DK (2011) The cost-effectiveness of a modestly effective HIV vaccine in the United States. Vaccine 29: 6113-6124.

39. Gruskin S, Tarantola D (2008) Universal Access to HIV prevention, treatment and care: assessing the inclusion of human rights in international and national strategic plans. AIDS 22 Suppl 2: S123-132.
40. Stein ZA (1990) HIV prevention: the need for methods women can use. Am J Public Health 80: 460-462. 